Crop Breeding and Applied Biotechnology 14: 76-81 2014

Brazilian Society of Plant Breeding. Printed in Brazil

\title{
ARTICLE
}

http://dx.doi.org/10.1590/1984-70332014v14n2a14

\section{A glutathione s-transferase confers herbicide tolerance in rice}

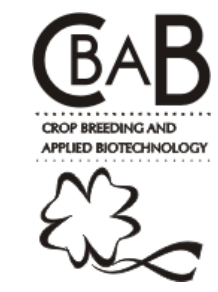

Tingzhang $\mathrm{Hu}^{1}$

Received 30 August 2012

Accepted 08 March 2013

\begin{abstract}
Plant glutathione S-transferases (GSTS) have been a focus of attention due to their role in herbicide detoxification. OsGSTL2 is a glutathione S-transferase, lambda class gene from rice (Oryza sativa L.). Transgenic rice plants over-expressing OsGSTL2 were generated from rice calli by the use of an Agrobacterium transformation system, and were screened by a combination of hygromycin resistance, PCR and Southern blot analysis. In the vegetative tissues of transgenic rice plants, the over-expression of OsGSTL2 not only increased levels of OSGSTL2 transcripts, but also GST and GPX expression, while reduced superoxide. Transgenic rice plants also showed higher tolerance to glyphosate and chlorsulfuron, which often contaminate agricultural fields. The findings demonstrate the detoxification role of OsGSTL2 in the growth and development of rice plants. It should be possible to apply the present results to crops for developing herbicide tolerance and for limiting herbicide contamination in the food chain.
\end{abstract}

Key words: Oryza sativa L., glutathione S-transferase, over-expression, herbicide resistance.

\section{INTRODUCTION}

GSTs are an ancient and multifunctional protein family encoded by a large gene family found ubiquitously in bacteria, fungi, animals and plants (Frova 2006). Plant GSTs have been the focus of attention due to their role in herbicide detoxification, which have been actively investigated during the last decades (Chi et al. 2011). Intensive studies of plant GSTs are required due to the considerable agronomic potential of these enzymes with regard to herbicide selectivity, tolerance and environmental safety (Edwards and Dixon 2005).

The complete identification in a genome-wide level revealed the presence of at least 79 GST genes in rice genome (Soranzo et al. 2004). Sequence analysis, and the organization of putative motifs indicated the potential diverse functions of GST gene family members in rice. Microarray data analysis revealed tissue-/organ-, and developmental stage-specific expression patterns of some rice GST genes. At least 31 GST genes responded to auxin and cytokinin plant hormones, 20 to abiotic stress, 32 to arsenate stress, and 48 to biotic stress. Many of GST genes in rice were commonly controlled by developmental processes, hormones, abiotic and biotic stresses (Jain et al. 2010).

GSTLs are one of the smallest clades of plant GST superfamily. Several GSTL features make them important targets for functional characterization. In particular, specific GSTLs are strongly upregulated in response to exposure to xenobiotic compounds, including herbicides, herbicide safeners and pharmaceuticals (Hershey and Stoner 1991, Dixon et al. 2002, Theodoulou et al. 2003). As with other GST classes, this correlation provides circumstantial evidence for a role in stress tolerance (Dixon et al. 2011). OsGSTL2 is a glutathione S-transferase, lambda class gene from rice, which showed response to chlorsulfuron. OsGSTL2 protein has a specific activity of GST (Hu et al. 2011). The purpose of this study was to over-express OsGSTL2 in rice and investigate the role of OsGSTL2 in protecting plants from the injury caused by herbicides.

\section{MATERIAL AND METHODS}

\section{Construction of transgene vector and plant transformation}

To construct OsGSTL2 over-expression vector, OSGSTL2 was cloned first into $\mathrm{pENTR/D-TOPO}$ vector, and then recombined into pHOS vector by LR reaction (Figure 1). The construction was confirmed by restriction digestion analysis, and then by sequencing. After transferring to Agrobacterium tumefaciens strain AGL0 through the freeze-thaw

${ }^{1}$ School of Life Science and Engineering, Chongqing Three Gorges University, Chongqing 404000, China. *E-mail: tzhu2002@yahoo.com.cn 


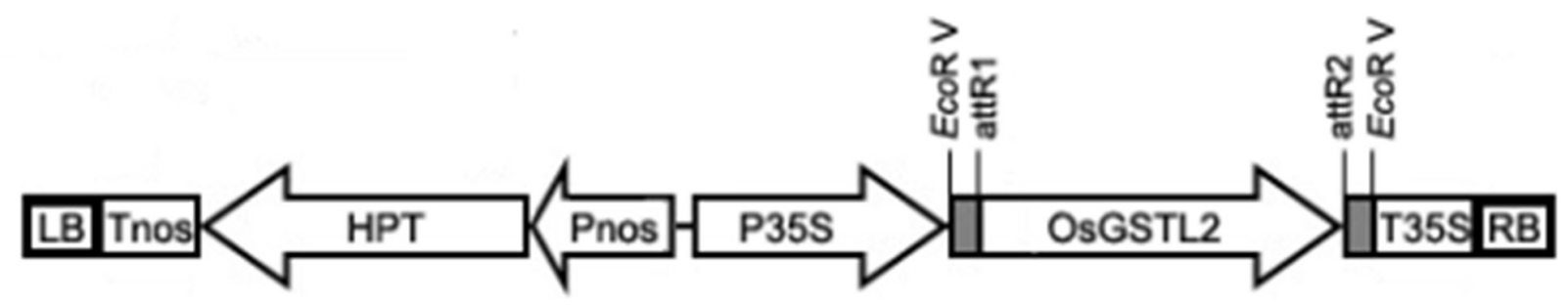

Figure 1. Structure of OSGSTL2 over-expression vector used for rice transformation. LB, left border; Tnos, nopaline synthase terminator; HPT, hygromycin phosphotransferase; Pnos, nopaline synthase promoter; P35S, CaMV 35S promoter; OsGSTL2, coding region of OsGSTL2; T35S, CaMV $35 \mathrm{~S}$ terminator, $R B$ right border.

method (Höfgen and Willmitzer 1988), the construct was used to transform embryogenic calli derived from Oryza sativa cv. Zhonghua through the Agrobacterium-mediated co-cultivation method (Hu 2008). Transgenic plants that rooted on hygromycin were transferred to vermiculitemixed soil (rich soil: vermiculite $=1: 3, \mathrm{~V} / \mathrm{V}$ ) in small pots, and grown at $28{ }^{\circ} \mathrm{C}$ under a $16 / 8 \mathrm{~h}$ light/dark photoperiod at an intensity of approximately $250 \mu \mathrm{E} \mathrm{m}^{-2} \mathrm{~s}^{-1}$.

\section{Confirmation of positive transgenic rice plants}

The positive transgenic plants were selected by PCR and Southern blot analysis. Genomic DNA of transgenic rice plants and non-transformed rice plants was extracted using Plant Genomic DNA Extraction kit (VOK-Bio, Beijing, China), and was used as models. Since HPT is closely adjacent to the target gene in the transformation constructs and not present in the non-transformed rice genome, it can be used to indicate the presence of the transgene. The primers hyg-f (5'-ATGAAAAAGCCTGAACTCACC-3') and hyg-r (5'-CCGGTCGGCATCTACTCT-3') were designed according to the HPT gene sequence. Amplification was carried out by initial denaturation at $94{ }^{\circ} \mathrm{C}$ for $2 \mathrm{~min}$ followed by 35 cycles of $94^{\circ} \mathrm{C}$ denaturation for $1 \mathrm{~min}, 58^{\circ} \mathrm{C}$ annealing for $1 \mathrm{~min}$, and $72{ }^{\circ} \mathrm{C}$ elongation for $1 \mathrm{~min}$.

About $15 \mu \mathrm{g}$ of genomic DNA of transgenic and nontransformed rice plants were digested by EcoRI. The digested genomic DNA was separated on a $0.8 \%$ agarose gel electrophoresis and was transferred to a Hybond nylon membrane (Amersham, Piscataway, USA). DNA was hybridized with a labeled DNA probe, which was generated from HPT gene located within the T-DNA borders of pHOS vector and radiolabeled with $\left[\alpha-{ }^{32} \mathrm{P}\right] \mathrm{dCTP}$, using random primer system. Standard procedures of Southern blot analysis were performed.

\section{Expression analysis of $O s G S T L 2$ gene}

Real-time PCR for analysis of OsGSTL2 expression was performed using total RNA from rice plant tissues. Total
RNA samples were isolated using Trizol reagent (GibcoBRL, USA), and subsequently treated with DNase I. RNAs were reverse-transcribed using the Superscript ${ }^{\mathrm{TM}}$ III RNase H-Reverse Transcriptase kit (Invitrogen, USA). Real-time PCR DNA amplification and analysis were carried out as described by $\mathrm{He}$ et al. (2012). DNA amplification and analysis were carried out using the CFX96 ${ }^{\mathrm{TM}}$ Real-Time System (C1000 ${ }^{\mathrm{TM}}$ Thermal Cycler). Using the quant Sybr green PCR Kit (Tianwei, China), and following the manufacturer's instructions, amplifications were performed with OsGSTL2-qf(5'-CGTTCAACAAAGCATCGTAC-3'), and OsGST-qr (5'-GCAAAAACTGTGGGTCCTGT-3'). Data were normalized to OsEF1 $\alpha$, which was amplified with primers OsEF1 $\alpha$-f ( 5 '-AGGGATGGGTCAAAAGGATGC-3') and OsEF1 $\alpha-r$ ( 5 '-GAGACAACACCGCCTGAATAGC-3'). Standard curves were constructed using serial cDNA dilutions. RT-PCR data were normalized with the relative efficiency of each primer pair. PCR amplification was performed using two-step cycling conditions of $98^{\circ} \mathrm{C}$ for $3 \mathrm{~min}$, followed by 40 cycles of $98^{\circ} \mathrm{C}$ for $2 \mathrm{~s}$, and $58^{\circ} \mathrm{C}$ for $10 \mathrm{~s}$. Amplification was followed by a melting curve analysis with continual fluorescence data acquisition from the $55-95{ }^{\circ} \mathrm{C}$ melt. Melt curve analysis of qPCR samples revealed that there was only one product for each gene primer reaction. Relative gene expression was determined using the Pfaffl method (Pfaffl 2001), and the non-transformed plant product was set as 1.0.

\section{Activity assay of enzyme and detection of superoxide}

OsGSTL2 over-expression transgenic seedlings and nontransformed rice seedlings cultured for $15 \mathrm{~d}$ were used to assay GST activity and glutathione peroxidase (GPX) activity. Crude protein extracts were prepared from rice plants (Hu 2008). Protein concentration was determined using the Bradford method (Bradford 1976). GST activity was measured spectrophotometrically (Takesawa et al. 2002). One unit of activity was defined as the amount of the enzyme that 
catalyzes the conversion of $1 \mu \mathrm{M} 2$,4-dinitrochlorobenzene (CDNB) per minute at $25^{\circ} \mathrm{C}$. Using the GSH-PX Kit (NJBI, China), and following the manufacturer's instructions, GPX activity was determined with $\mathrm{H}_{2} \mathrm{O}_{2}$ as substrate. One unit of activity was defined as the amount of the enzyme that catalyzes the consumption of $1 \mu \mathrm{M} \mathrm{H}_{2} \mathrm{O}_{2}$ per minute. Transgenic seedlings and non-transformed rice seedlings cultured for a month were used to detect superoxide. Superoxide levels were visually detected with nitro blue tetrazolium (NBT) described previously (Yang et al. 2004).

\section{Assay for herbicide tolerance of transgenic rice plants}

In order to measure responses to herbicide, transgenic seedlings and non-transformed rice seedlings cultured for $12 \mathrm{~d}$ were treated with $100 \mu \mathrm{mol} \mathrm{L}^{-1}$ glyphosate and $0.02 \%$ chlorsulfuron for $24 \mathrm{~h}$, respectively. Seedlings were subsequently transferred into vermiculite-mixed soil and grown as described above.

\section{RESULTS AND DISCUSSION}

\section{Generation and confirmation of transgenic rice plants}

Transgenic rice plants were generated to test OsGSTL2 physiological function in rice. Plant expression vector was introduced to Agrobacterium tumefaciens AGL0, and transformed into Oryza sativa cv. Zhonghua. Ten transgenic lines were obtained and the transformants were verified by PCR analysis. HPT gene fragments $(1,042 \mathrm{bp})$ were detected in selected independent lines and in positive control OsGSTL2 over-expression vector, whereas they were not found in non-transformed plants (Figure 2A). Southern blot analysis was used to further confirm the presence of transgene, and determine insertion copy number. Genomic DNA samples of transgene rice lines and non-transformed rice plants were hybridized with a radiolabeled $H P T$ gene fragment as probe. Since HPT is adjacent to the target gene OSGSTL2 in the transformation constructs, and is not present in the wildtype rice genome, its presence in the blot should indicate the copy number of the transgene. The result showed that the HPT hybridizing fragments were detected in all ten of the independent transgenic lines, but they were not found in non-transformed rice (Figure 2B). Three independent transgenic lines were selected for further analyses.

\section{Expression of $O s G S T L 2$ in transgenic rice plants}

To investigate the in vivo role of OSGSTL2 in rice, OsGSTL2 was over-expressed in transgenic rice plants.
Independent transgenic lines were selected based on PCR analysis. Real time RT-PCR revealed that expression level of OsGSTL2 was higher in the transformants than in the non-transformed control. Os GSTL2 transcripts in transgenic lines 1,2 , and 3 were $4.29,3.16$, and 5.65-fold of that observed in non-transformed plants (Figure 3), respectively. These findings suggest that OsGSTL2 gene introduced in transgenic rice plants was indeed over-expressed.
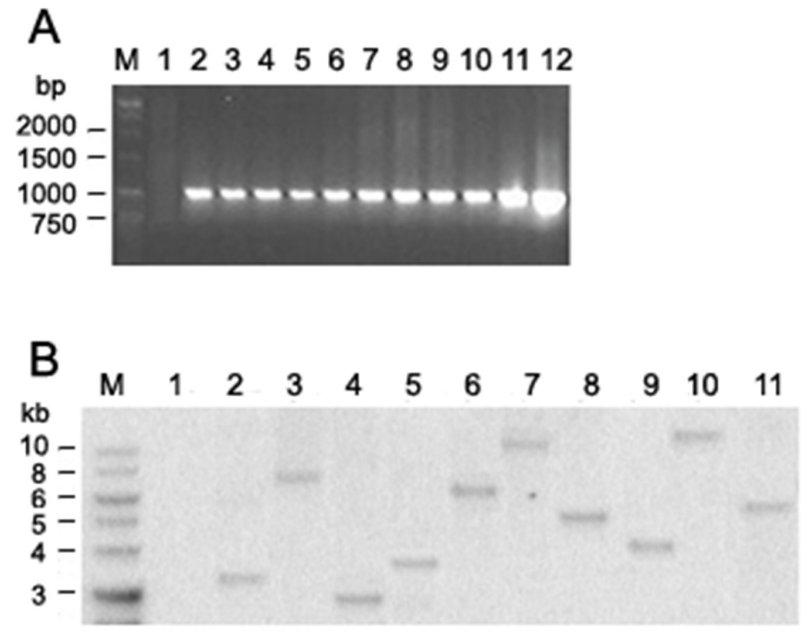

Figure 2. Confirmation of positive transgenic rice plants. A. PCR analysis; B. Southern blot analysis. Lane M, DNA ladder; Lane 1, negative control non-transformed plants; Lane 2-11, independent transgenic lines; Lane 12, Positive control OSGSTL2 over-expression vector.

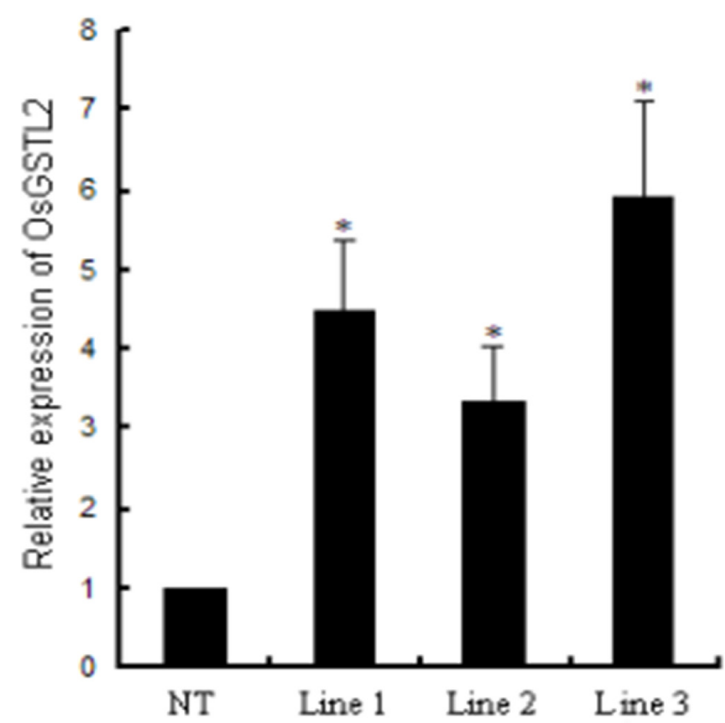

Figure 3. Real time RT-PCR analysis expression of OsGSTL2 in transgenic rice plant. NT, non-transformed plants; Line 1-3, independent transgenic lines. Data are representative of three separate experiments performed in triplicates. Results are mean \pm SD. Asterisks above the bars indicate differences between mean values measured in the indicated transgenic line compared to non-transformed plants is $P<0.05$ (Student's $t$-test). 


\section{Transgenic rice has higher activities of GST and GPX and lower superoxide}

GST activity of crude extracts from transgenic seedlings and non-transformed rice seedlings was measured with CDNB as substrate. Transformants contained higher levels of GST activities than non-transformed rice. GST activity of lines 1, 2 and 3 were 2.07, 1.79 and 2.40-fold of that observed in non-transformed plants, respectively (Figure 4A). GPX activities in OsGSTL2 transgenic lines were measured with $\mathrm{H}_{2} \mathrm{O}_{2}$ as substrate. GPX activity in transgenic lines was higher than the non-transformed rice as well. GPX activity in transgenic lines 1, 2 and 3 were 1.61, 1.50, and 1.71-fold of that detected in non-transformed plants, respectively (Figure 4B). GPX activities, which could degrade superoxide levels, were higher in transgenic plants as well.

Superoxide detection was performed during the vegetative growth phase of plants. Leaves of rice seedlings were stained with NBT for visually detect superoxide. Leaves of OsGSTL2 transgenic rice seedlings contain lower superoxide than those of non-transformed rice plants (Figure 5).

GSTs are known to protect plants against oxidative stress induced by biotic and abiotic agents. Some GSTs also have secondary activities as glutathione peroxidase and can protect the cells/organisms from oxidative damage. GSTs can eliminate membrane lipid peroxides, as well as products derived from oxidative DNA degradation via GSH conjugation (Berhane et al. 1994).

\section{Transgenic rice has higher tolerance to herbicide}

OsGSTL2 transgenic rice plants grew normally, and phenotypes were indistinguishable with non-transformed rice plants. To examine the role of OSGSTL2 in plants,

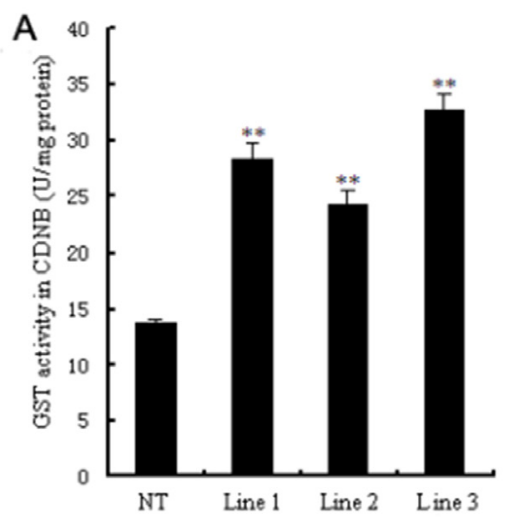

12-day-old seedlings of OsGSTL2 transgenic rice and non-transformed plants were incubated with $100 \mu \mathrm{mol} \mathrm{L}^{-1}$ glyphosate or $0.02 \%$ chlorsulfuron for $24 \mathrm{~h}$, respectively. After glyphosate treatment, seedlings were also cultivated for $10 \mathrm{~d}$; although all treated plants grew more slowly than the non-treated ones, the non-transformed plants grew even more slowly in comparison to the transgenic plants (Figure 6A). After chlorsulfuron treatment, seedlings were also cultivated for $10 \mathrm{~d}$, all the treated plants grew slowly and became yellow. However, the phenotypic difference of transgenic rice seedlings and non-transformed seedlings was obvious. The non-transformed rice plants showed more severe yellowing and grew more slowly compared with the transgenic rice plants (Figure 6B). These results suggest that

NT

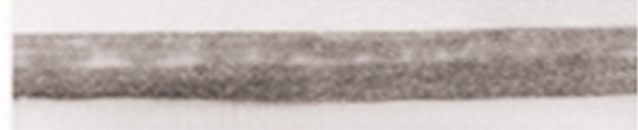

Line 1

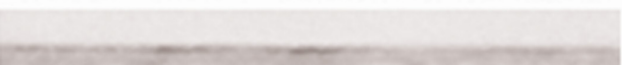

Line 2

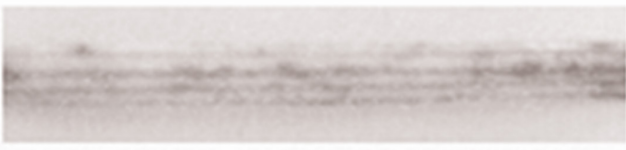

Line 3

Figure 5. Detection of superoxide level by NBT staining in rice leaves. NT, non-transformed plants; Lines 1 to 3, independent transgenic lines.

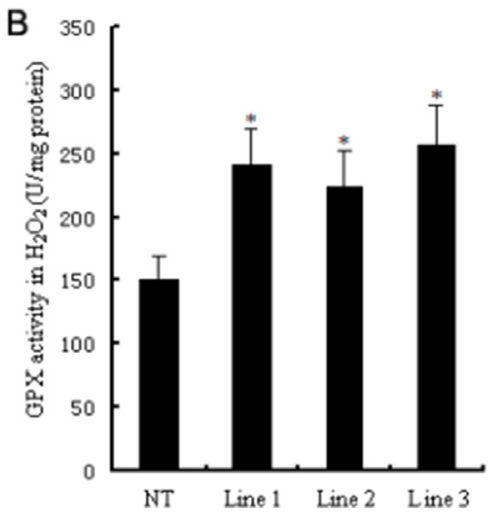

Figure 4. Activities of GST and GPX in transgenic rice plant. A. GST activity; B. GPX activity. NT, non-transformed plants; Line 1-3, independent transgenic lines. Data are representative of three separate experiments performed in triplicates. Results are mean \pm SD. $*$ and $* *$ above the bars indicate differences between mean values measured in the indicated transgenic line compared to non-transformed plants is $\mathrm{P}<0.05$ and $\mathrm{P}<0.001$, respectively (Student's $t$-test). 

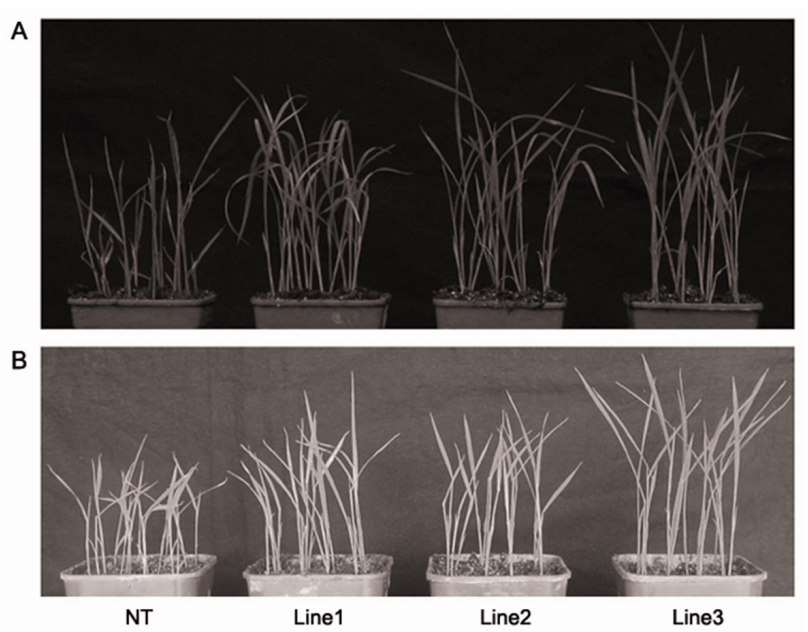

Figure 6. The effect of glyphosate and chlorsulfuron treatment in transgenic lines. A. After $100 \mu \mathrm{mol} \mathrm{L}^{-1}$ glyphosate treatment for $24 \mathrm{~h}$ and then the seedling was cultivated for $10 \mathrm{~d}$; B. After $0.02 \%$ chlorsulfuron treatment for $24 \mathrm{~h}$ and then the seedling was cultivated for $10 \mathrm{~d}$. NT, nontransformed plants; Line 1-3, independent transgenic lines.

the over-expression of OsGSTL2 improves glyphosate and chlorsulfuron tolerance of rice plants.

Earlier work had shown that over-expression of some GSTs in plants improved herbicide tolerance. For example, transgenic wheat plants expressing the maize GST-27 gene were resistant to chloroacetanilide herbicide alachlor and dimethenamid, and thiocarbamate herbicide S-ethyldipropylthio-carbamate (Milligan et al. 2001). Transgenic tobacco plants expressing the cotton Gst-crl gene showed much higher expression levels of GST and GPX activities, and showed an enhanced resistance to oxidative stress induced by a low concentration of methyl viologen (Yu et al. 2003). Transgenic tobacco plants expressing maize glutathione
$S$-transferase I presented substantially higher tolerance to alachlor compared to non-transgenic plants (Karavangeli et al. 2005). Over-expression of a specific soybean $\mathrm{GmG}$ STU4 gene improved diphenyl ether and chloroacetanilide herbicide tolerance of transgenic tobacco plants (Benekos et al. 2010).

\section{CONCLUSIONS}

Transgenic rice plants over-expressing OsGSTL2 gene showed higher levels of OsGSTL2 gene expression in the absence of any treatment, increased levels of GST and GPX enzyme activities, and showed lower level of superoxide compared to wild type plants. Transgenic rice seedlings had higher tolerance to glyphosate and chlorsulfuron than nontransformed rice seedlings. Transgenic plants detoxifying herbicide are potentially useful biotechnological tools for the development of phytoremediation system for the degradation of herbicide pollutants in agricultural fields. The present results are potentially extendable to other crops in programs aiming at developing herbicides tolerance and at limiting herbicide contamination in the food chain.

\section{ACKNOWLEDGMENTS}

This work was funded by the Natural Science Foundation Project of Chongqing Science and Technology Committee (cstc2011jjA80027, cstc2012jjA80009), and the University Innovation Team Construction Project of Chongqing Education Committee (201040). Project supported by Scientific and Technological Research Program of Chongqing Municipal Education Commission (Grant No. KJ121106 and KJ131101) and the Natural Science Foundation Project of Chongqing Three Gorges University (11ZD-16).

\section{Uma glutationa s-transferase confere tolerância a herbicida em arroz}

Resumo - Plantas glutationa s-transferase (GSTS) têm sido foco da atenção devido ao seu papel na detoxificação de herbicida. OsGSTL2 é uma glutationa s-transferase, gene da classe lambda de rice (Oryza sativa L.). Plantas transgênicas de arroz superexpressando OsGSTL2 foram geradas de "calus" de arroz via sistema de transformação de Agrobacterium, e foram avaliadas por uma combinação de resistência a higromicina, PCR e análise de "Southern blot". Nos tecidos vegetativos das plantas transgênicas, a superexpressão de OsGSTL2 não somente incrementou os níveis de transcritos OsGSTL2, mas também a expressão de GST e GPX, enquanto reduziu superóxido. Plantas transgênicas também mostraram mais alta tolerância a glifosato e clorosulfuron, os quais frequentemente contaminam solos agrícolas. Essas descobertas demonstram o papel de detoxificação de OsGSTL2 no crescimento e desenvolvimento de plantas de arroz. A partir delas será possivel também aplicar tais resultados a outros cultivos para desenvolvimento de tolerância a herbicida e para limitar a contaminação com esse agrotóxico na cadeia alimentar.

Palavras-chave: Oryza sativa L., glutationa S-transferase, superexpressão, resistência a herbicida.

\section{REFERENCES}

Benekos K, Kissoudis C, Nianiou-Obeidat I, Labrou N, Madesis P, Kalamaki M, Makris A and Tsaftaris A (2010) Overexpression of a specific soybean GmGSTU4 isoenzyme improves diphenyl ether and chloroacetanilide herbicide tolerance of transgenic tobacco plants.
Journal of Biotechnology 150: 195-201.

Berhane K, Widersten M, Engström A, Kozarich JW and Mannervik B (1994) Detoxication of base propenals and other alpha, betaunsaturated aldehyde products of radical reactions and lipid peroxidation by human glutathione transferases. Proceedings of the 
National Academy of Sciences of the United States of America 91: 1480-1484.

Bradford NM (1976) A rapid and sensitive method for the quantitation of microgram quantities of protein utilizing the principle of protein-dye binding. Analytical Biochemistry 72: 248-254.

Chi Y, Cheng Y, Vanitha J, Kumar N, Ramamoorthy R, Ramachandran S and Jiang SY (2011) Expansion mechanisms and functional divergence of the glutathione s-transferase family in sorghum and other higher plants. DNA Research 18: 1-16.

Dixon DP, Davis BG and Edwards R (2002) Functional divergence in the glutathione transferase superfamily in plants-identification of two classes with putative functions in redox homeostasis in Arabidopsis thaliana. The Journal of Biological Chemistry 277: 30859-30869.

Dixon DP, McEwen AG, Lapthorn AJ and Edwards R (2003) Forced evolution of a herbicide detoxifying glutathione transferase. The Journal of Biological Chemistry 278: 23930-23935.

Dixon DP, Steel PG and Edwards R (2011) Roles for glutathione transferases in antioxidant recycling. Plant Signaling \& Behavior 6: $1223-1227$.

Edwards R and Dixon DP (2005) Plant glutathione transferases. Methods in Enzymology 401: 169-186.

Frova C (2006) Glutathione transferases in the genomics era: new insights and perspectives. Biomolecular Engineering 23: 149-169.

He S, Tan L, Hu Z, Chen G, Wang G and Hu T (2012) Molecular characterization and functional analysis by heterologous expression in $E$. coil under diverse abiotic stresses for OSLEA5, the atypical hydrophobic LEA protein from Oryza sativa L. Molecular Genetics and Genomics 287: 39-54.

Hershey HP and Stoner TD (1991) Isolation and characterization of cDNA clones for RNA species induced by substituted benzenesulfonamides in corn. Plant Molecular Biology 17: 679-690.

Höfgen R and Willmitzer L (1988) Storage of competent cells for Agrobacterium transformation, Nucleic Acids Research 16: 9877.

Hu TZ (2008) OsLEA3, a late embryogenesis abundant protein gene from rice, confers tolerance to water deficit and salt stress to transgenic rice. Russian Journal of Plant Physiology 55: 530-537.
Hu T, He S, Huang X, Deng L and Wang G (2011) Cloning, molecular characterization and heterologous expression of a glutathione S-transferase gene in rice. Bioorganichesaia Khimiia 37: 386-392.

Jain M, Ghanashyam C and Bhattacharjee A (2010) Comprehensive expression analysis suggests overlapping and specific roles of rice glutathioneS-transferase genes during development and stress responses. BMC Genomics 11: 73.

Karavangeli M, Labrou NE, Clonis YD and Tsaftaris A(2005) Development of transgenic tobacco plants overexpressing maize glutathione S-transferase I for chloroacetanilide herbicides phytoremediation. Biomolecular Engineering 22: 121-128.

Milligan AS, Daly A, Parry MAJ, Lazzeri PA and Jepson I (2001) The expression of a maize glutathione S-transferase in transgenic wheat confers herbicide tolerance, both in planta and in vivo. Molecular Breeding 7: 301-305.

Pfaffl MW (2001) A new mathematical model for relative quantification in real-time RT-PCR. Nucleic Acids Research 29: e45

Soranzo N, Sari Gorla M, Mizzi L, De Toma G and Frova C (2004) Organisation and structural evolution of the rice glutathione S-transferase gene family. Molecular Genetics and Genomics 271: 511-521.

Takesawa T, Ito M, Kanzaki H, Kameya N and Nakamura I (2002) Overexpression of glutathione S-transferase in transgenic rice enhances germination and growth at low temperature. Molecular Breeding 9: 93-101.

Theodoulou FL, Clark IM, He XL, Pallett KE, Cole DJ and Hallahan DL (2003) Co-induction of glutathione-S-transferases and multidrug resistance associated protein by xenobiotics in wheat. Pest Management Science 59: 202-214.

Yang Y, Qi M and Mei C (2004) Endogenous salicylic acid protects rice plants from oxidative damage caused by aging as well as biotic and abiotic stress. The Plant Journal 40: 909-919.

Yu T, Li YS, Chen XF, Hu J, Chang X and Zhu YG (2003) Transgenic tobacco plants overexpressing cotton glutathione S-transferase (GST) show enhanced resistance to methyl viologen. Journal of Plant Physiology 160: 1305-1311 